\title{
Effect of gas pressure on properties of FePt film sputtered on polymer substrate
}

L. T. Nguyen ${ }^{\text {a) }}$

SMI, MESA Research Institute, University of Twente, P.O. Box 217, 7500 AE Enschede, The Netherlands

A. Lisfi

Department of Physics, Morgan State University, 1700 E. Cold Spring Lane, Baltimore, Maryland 21251

J. C. Lodder

SMI, MESA Research Institute, University of Twente, P.O. Box 217, 7500 AE Enschede, The Netherlands

(Presented on 9 January 2004)

FePt thin films (70 nm thick) have been prepared by dc sputtering under a variable Ar pressure $\left(4 \times 10^{-3}-4 \times 10^{-2} \mathrm{mb}\right)$ and have been annealed at temperatures ranging from 300 to $400^{\circ} \mathrm{C}$. With increasing $\mathrm{Ar}$ pressure, the ordering process requires a lower annealing temperature. However, further increase of Ar pressure deteriorates the crystallinity of the film which hinders the transformation from fcc to fct structure. The structural analyses show a strong correlation between the ordering process and the microstructure. (C) 2004 American Institute of Physics.

[DOI: $10.1063 / 1.1688674]$

\section{INTRODUCTION}

The equiatomic FePt ordered alloy is a very promising material for ultrahigh recording density. Its high magnetic anisotropy $\left(K_{u} \sim 10^{7} \mathrm{~J} / \mathrm{m}^{3}\right)$ can allow a stable magnetization in nano-structures with grain size down to $2 \mathrm{~nm}$ and recording densities beyond $1 \mathrm{~Tb} / \mathrm{in}^{2}{ }^{2}{ }^{1}$ However, a high-temperature treatment such as substrate heating during deposition or post deposition annealing is necessary to achieve the ordered phase with high $K_{u}$. The ordering temperature can be as high as $550^{\circ} \mathrm{C}, 2,3$ which is not suitable for manufacturing process of recording media. So far, some approaches have been proposed to reduce the ordering temperature of this material. For example, a multilayered $\mathrm{Fe} / \mathrm{Pt}$ film was effective in reducing the ordering temperature to $350{ }^{\circ} \mathrm{C} .{ }^{4}$ On the other hand introducing Ag underlayer can lower the ordering temperature of $L 1_{0}$ FePt alloys and produce textured (001) films. ${ }^{5}$ The formation of the ternary $\mathrm{FePtCu}$ alloy is considered to play the major role in reducing the temperature for the disordered-ordered transformation to $300{ }^{\circ} \mathrm{C} .{ }^{6}$ Recently, we have stabilized the fct phase at $350^{\circ} \mathrm{C}^{7}$ in films deposited on polyimide substrate. There are some reasons for the formation of fct phase at rather low temperature. First, the weak adhesion between the metallic layer and the polymer due to their weak dipole-dipole interaction may be one of the origins of such effect. Thus the thermal diffusion process to form fct structure occurs easier compared to the case of FePt sputtered on rigid substrates. Other factors can influence the ordering process: the stress in the films or the low thermal conductivity of the polymer which could increase the substrate temperature during the sputtering process. The detail discussion of the origins of this effect will be presented in Ref. 7. In this article, we report the influence of sputter pres-

\footnotetext{
a) Author to whom correspondence should be addressed; electronic mail: 1.t.nguyen@utwente.nl
}

sure on the properties of the FePt films deposited on polymer substrate. The aim of this work is to better understand the ordering process of FePt film on polymer substrate as well as optimize the preparation conditions to achieve fct structure at low temperature.

\section{EXPERIMENTS}

FePt thin films were prepared by dc sputtering from a composite target $\left(\mathrm{Fe}_{50} \mathrm{Pt}_{50}\right)$. The distance between the sputter gun and the substrate is $4 \mathrm{~cm}$. The Ar pressure was varied from $4 \times 10^{-3}$ to $4 \times 10^{-2} \mathrm{mb}$ while the film thickness was fixed at $70 \mathrm{~nm}$. The substrate consists of $20 \mu \mathrm{m}$ thick polyimide coated with $2 \mu \mathrm{m} \mathrm{Cu}$ at the back side. The $\mathrm{Cu}$ layer may enhance the thermal resistance of the substrate since no damage of the films was observed at annealing temperature as high as $400{ }^{\circ} \mathrm{C}$. The composition of the films was estimated from the $\mathrm{x}$-ray photoelectron spectroscopy measurement to be $\mathrm{Fe}_{55} \mathrm{Pt}_{45}$. The samples were annealed in vacuum $\left(2 \times 10^{-5} \mathrm{mb}\right)$ at temperatures ranging from 300 to $400^{\circ} \mathrm{C}$ between 1 and $10 \mathrm{~h}$. Structural analyses have been investigated with $\mathrm{x}$-ray diffraction (XRD) and atomic force microscopy (AFM), whereas magnetic measurements have been performed using vibrating sample magnetometer with the maximum applied field of $3 \mathrm{~T}$.

\section{RESULTS AND DISCUSSION}

All the as-deposited films are magnetically soft indicating the formation of fcc structure. Upon annealing at $300{ }^{\circ} \mathrm{C}$ for various periods of 1,5 , and $10 \mathrm{~h}$, the films are still magnetically soft except the one sputtered at Ar pressure of 2 $\times 10^{-2} \mathrm{mb}$. This film exhibits a coercivity $H_{c}$ of $200 \mathrm{kA} / \mathrm{m}$ after $5 \mathrm{~h}$ annealing (Fig. 1). The shape of the hysteresis loop confirms the existence of soft (fcc) and hard (fct) phases in the film and its distortion indicates a strong coupling between both phases. After $10 \mathrm{~h}$ of annealing a significant in- 


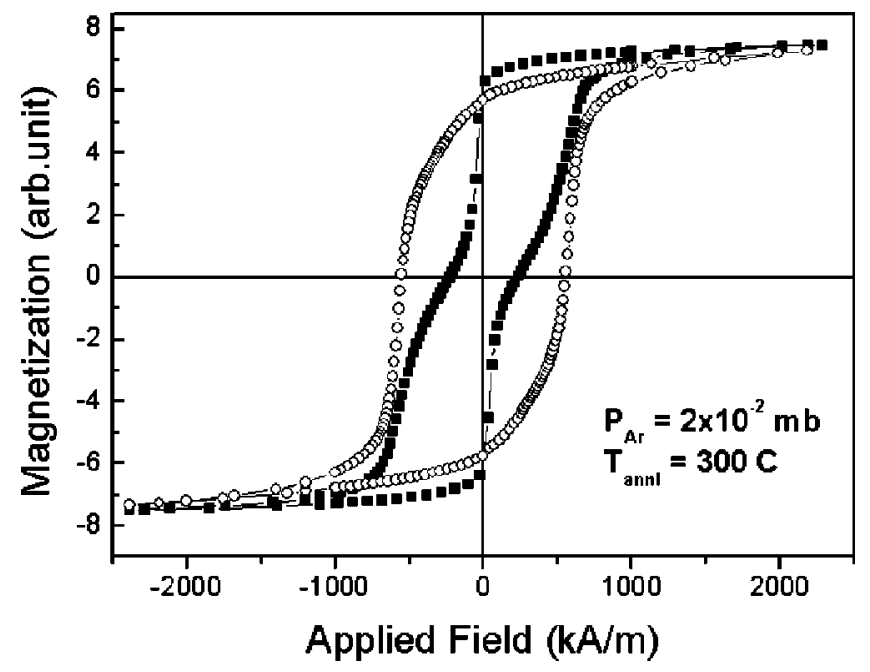

FIG. 1. Hystersis loops of the film sputtered at $2 \times 10^{-2} \mathrm{mb}$ and annealed at $300{ }^{\circ} \mathrm{C}$ for $5 \mathrm{~h}$ (square) and for $10 \mathrm{~h}$ (circle).

crease of $H_{c}$ is noticed $(530 \mathrm{kA} / \mathrm{m})$. Additionally the similar value of $H_{c}$ in both loops (in-plane and out-of plane) suggests a random distribution of $c$ axes of fct phase. The high coercivity achieved at low temperature is an interesting result since temperatures above $550{ }^{\circ} \mathrm{C}$ are required to stabilize fct structure for FePt films sputtered at room temperature. At annealing temperature of $350{ }^{\circ} \mathrm{C}$ a drastic increase of $H_{c}$ is observed for films grown at $\mathrm{Ar}$ pressure below 4 $\times 10^{-2} \mathrm{mb}$ even for short time of annealing as illustrated in Fig. 2. Moreover, $H_{c}$ exhibits a saturation behavior at 700 $\mathrm{kA} / \mathrm{m}$ with annealing time. However, the sample with highest Ar pressure of $4 \times 10^{-2} \mathrm{mb}$ is still magnetically soft. Further rising of annealing temperature does not improve the coercivity much. Therefore, the annealing time at $400{ }^{\circ} \mathrm{C}$ was restricted for $1 \mathrm{~h}$ in this study.

In all the samples, we observe the tendency that there is an optimal Ar pressure for the transformation from fcc to fct structure. The ordering process occurs easier with increasing Ar pressure. However, at a certain value of Ar pressure (4 $\times 10^{-2} \mathrm{mb}$ ) the film is still magnetically soft at $400^{\circ} \mathrm{C}$, the

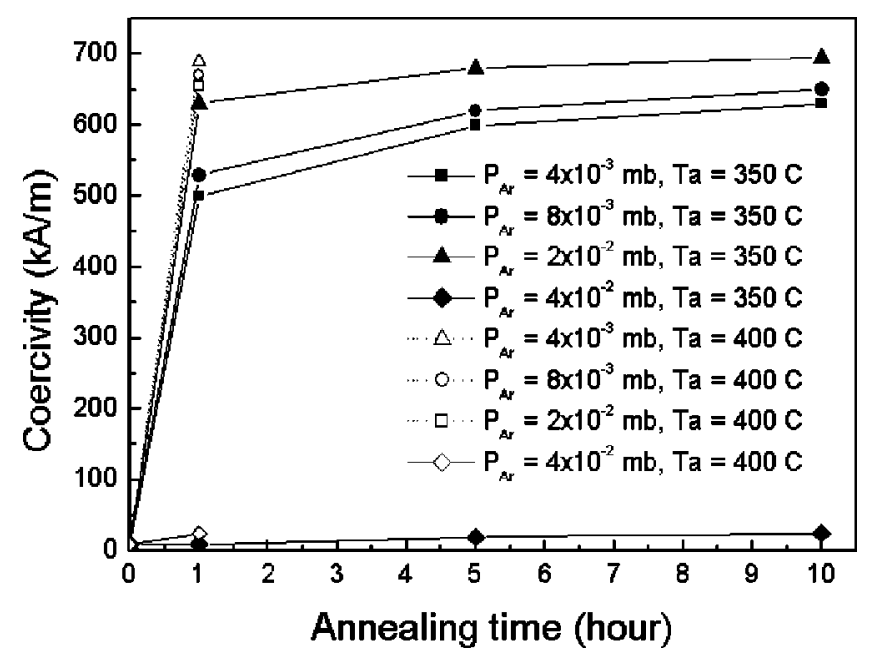

FIG. 2. Dependence of coercivity on annealing time at different Ar pressures and temperatures.

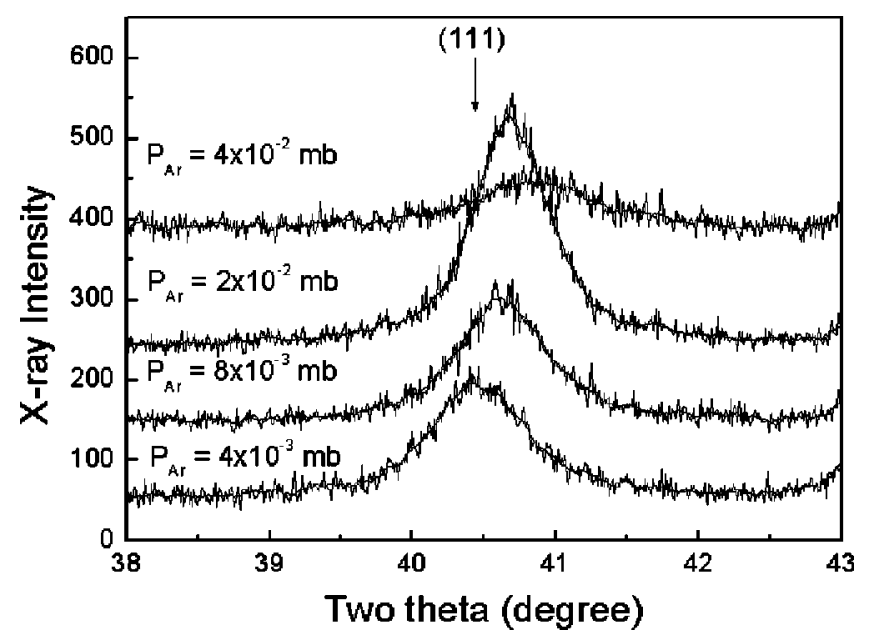

FIG. 3. X-ray patterns of as-deposited films with different Ar pressures.

highest temperature in our experiment. To have more understanding about the ordering process in such films, XRD measurements have been carried out. Figure 3 depicts the XRD results of as-deposited samples with different Ar pressures. In all the films, (111) texture of fcc structure is observed. At the pressure of $4 \times 10^{-3} \mathrm{mb}$, the (111) peak is already slightly shifted to higher angle compared to the (111) peak of the bulk fcc structure of FePt. As the Ar pressure increases, this peak is more shifted toward higher angle indicating the reducing of the (111) plane spacing. At the pressure of 4 $\times 10^{-2} \mathrm{mb}$, however, the peak is much broader with very weak intensity indicating a low crystallinity in this film. The shift of (111) peak of disordered fcc phase has been reported in other studies of FePt films annealed at temperatures below $300{ }^{\circ} \mathrm{C} .{ }^{8,9}$ At such temperatures, the fcc phase undergoes some progressive modifications of structure features and local environment before the transformation to ordered fct structure occurs. These modifications cause a strain relaxation in the films which results in a drop of (111) spacing. The transition state of fcc phase is highly dependent on the presence of microstrains and short range order in the as deposited films. In our case, the shift of (111) peak probably indicates the existence of the transition state of fcc phase during the film growth. Since the binding energy of polymer substrate with the adatoms is small, the enhancement of surface diffusion of the adatoms can favor the formation of the transition fcc phase. With increasing Ar pressure, the fraction of fcc phase in the transition state can be increased. This explains why the transition from fcc to fct occurs easier with the films sputtered at higher Ar pressures.

The x-ray patterns of the samples annealed at $350{ }^{\circ} \mathrm{C}$ for $10 \mathrm{~h}$ are presented in Fig. 4. The peak of (111) plane is already shifted to $41^{\circ}$, which is close to the (111) peak position of the fct structure $\left(41.1^{\circ}\right)$. Beside the (111) peak, other characteristic peaks of fct structure are also observed but with low intensities. Thus at this annealing temperature, the transition from fec to fct is not fully achieved. This is in agreement with our magnetic measurements since the maximum coercivity of our films is around $700 \mathrm{kA} / \mathrm{m}$, whereas in fully ordered FePt films $H_{c}$ can be as high as $900 \mathrm{kA} / \mathrm{m} .{ }^{2}$ For the film sputtered at pressure of $4 \times 10^{-2} \mathrm{mb}$, however, the 


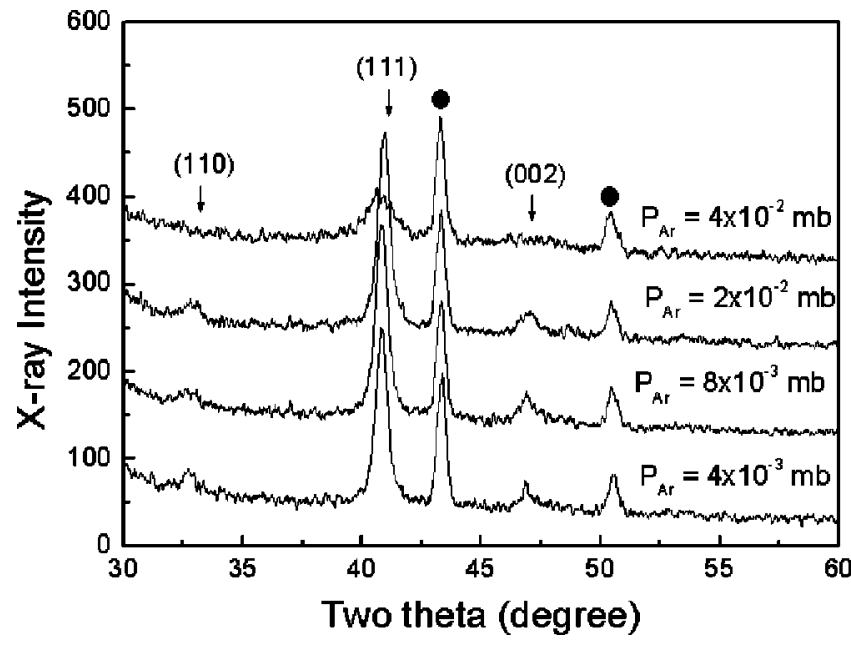

FIG. 4. X-ray patterns of the films annealed at $350{ }^{\circ} \mathrm{C}$ for $5 \mathrm{~h}$ with different Ar pressures. The circles denote the diffraction peaks from the substrate.

transformation process has not occurred since there is no change in the $\mathrm{x}$-ray pattern.

Figure 5 shows the microstructure of the as deposited films measured by AFM. At low Ar pressure, the surface of the film is quite smooth indicating a continuous film. At the pressure of $2 \times 10^{-2} \mathrm{mb}$, the topography of the film consists of a granular structure with average size of $15 \mathrm{~nm}$. It is noted that the highest coercivities at different annealing times are obtained in this sample. Thus this microstructure of FePt films with nanosize grains probably enhances the formation of fct phase because the diffusion process can be stimulated at the grain boundaries. Further increase of Ar pressure re-
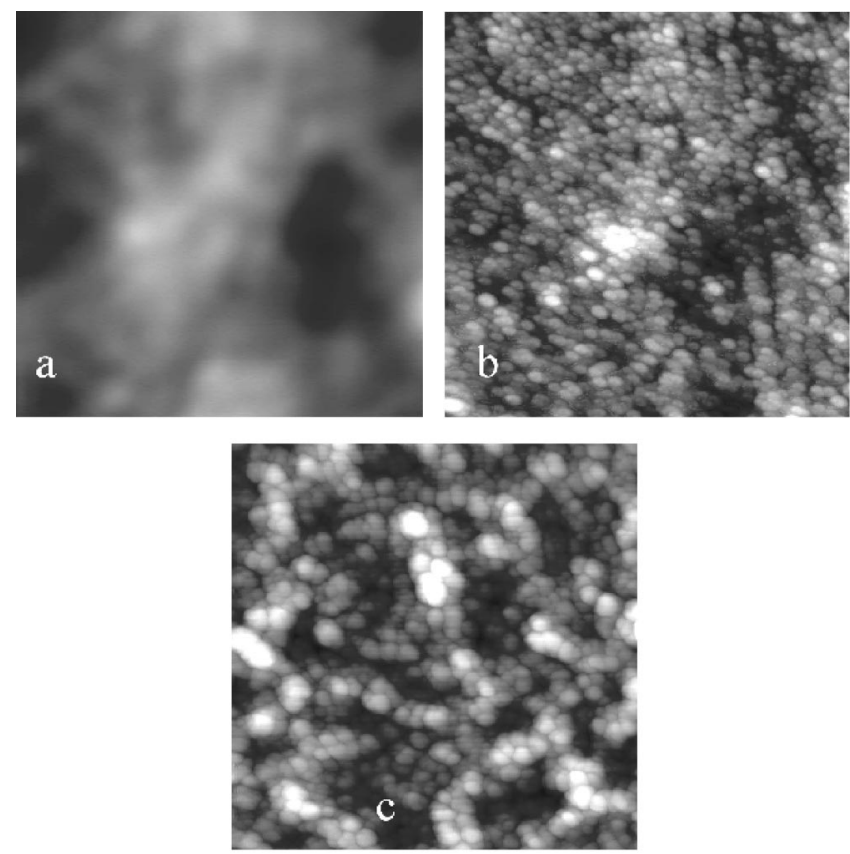

FIG. 5. $(1 \times 1) \mu \mathrm{m}$ AFM images of as deposited films sputtered at 4 $\times 10^{-3} \mathrm{mb}(\mathrm{a}), 2 \times 10^{-2} \mathrm{mb}(\mathrm{b})$, and $4 \times 10^{-2} \mathrm{mb}(\mathrm{c})$.
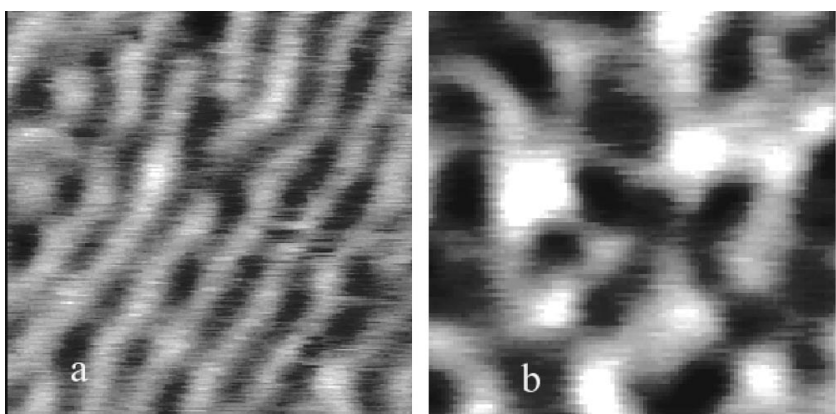

FIG. 6. $(1 \times 1) \mu \mathrm{m}$ MFM images of as deposited (a) and annealed at $350{ }^{\circ} \mathrm{C}$ for $5 \mathrm{~h}(\mathrm{~b})$ of films sputtered at $4 \times 10^{-3} \mathrm{mb}$.

sults in very rough film with high porosity. In this film the intercrystalline voids may hinder the diffusion process. This fact could explain why in such film the ordering process could not occur at annealing temperature up to $400^{\circ} \mathrm{C}$.

The domain structures of the film sputtered at 4 $\times 10^{-3} \mathrm{mb}$ are presented in Fig. 6 . In the as deposited state, the strong coupling of fcc phase results in a stripe domain structure [Fig. 6(a)], whereas random domain structure is observed after $5 \mathrm{~h}$ of annealing at $350{ }^{\circ} \mathrm{C}$ [Fig. 6(b)].

\section{CONCLUSION}

In conclusion, the ordering process of FePt is strongly dependent on the Ar sputtering pressure. The optimal pressure is around $2 \times 10^{-2} \mathrm{mb}$. At this pressure, the transformation from fcc to fct can even occur at $300^{\circ} \mathrm{C}$ for long annealing time. A maximum coercivity of $700 \mathrm{kA} / \mathrm{m}$ can be obtained after annealing at $350{ }^{\circ} \mathrm{C}$ for $1 \mathrm{~h}$. However, in order to have more insight knowledge about structure properties, further microstructure studies such as high resolution transmission electron microscopy are in progress. This type of FePt films sputtered on polymer substrate could be interesting for high density recording on flexible medium. In order to grow such films with perpendicular anisotropy, using some additives such as $\mathrm{Ag}$ and $\mathrm{B}_{2} \mathrm{O}_{3}$ might be a solution since such materials are reported to promote (001) texture. ${ }^{10,11}$

${ }^{1}$ D. Weller, A. Moser, L. Folks, M. E. Best, W. Lee, M. F. Toney, M. Schwickert, J. U. Thiele, and M. F. Doerner, IEEE Trans. Magn. 36, 10 (2000).

${ }^{2}$ C. M. Kuo, P. C. Kuo, H. C. Wu, Y. D. Yao, and C. H. Lin, J. Appl. Phys. 85, 4886 (1999)

${ }^{3}$ K. Coffey, M. A. Parker, and J. K. Howard, IEEE Trans. Magn. 31, 2737 (1995)

${ }^{4}$ C. P. Luo and D. J. Sellmyer, IEEE Trans. Magn. 31, 2764 (1995).

${ }^{5}$ Y. N. Hsu, S. Jeong, D. E. Laughlin, and D. N. Lambeth, J. Appl. Phys. 89, 7068 (2001)

${ }^{6}$ T. Maeda, T. Kia, A. Kikitsu, T. Nagase, and J. Akiyama, Appl. Phys. Lett. 80, 2147 (2002).

${ }^{7}$ L. T. Nguyen et al. (unpublished).

${ }^{8}$ K. W. Wierman, C. L. Platt, J. K. Howard, and F. E. Spada, J. Appl. Phys. 93, 7160 (2003).

${ }^{9}$ F. E. Spada, F. T. Parker, C. L. Platt, and J. K. Howard, J. Appl. Phys. 94, 5123 (2003).

${ }^{10}$ Y. Shao, M. L. Yan, and D. J. Sellmyer, J. Appl. Phys. 93, 8152 (2003).

${ }^{11}$ C. P. Luo, S. H. Liou, L. Gao, Y. Liu, and D. J. Sellmyer, Appl. Phys. Lett. 77, 2225 (2000) 